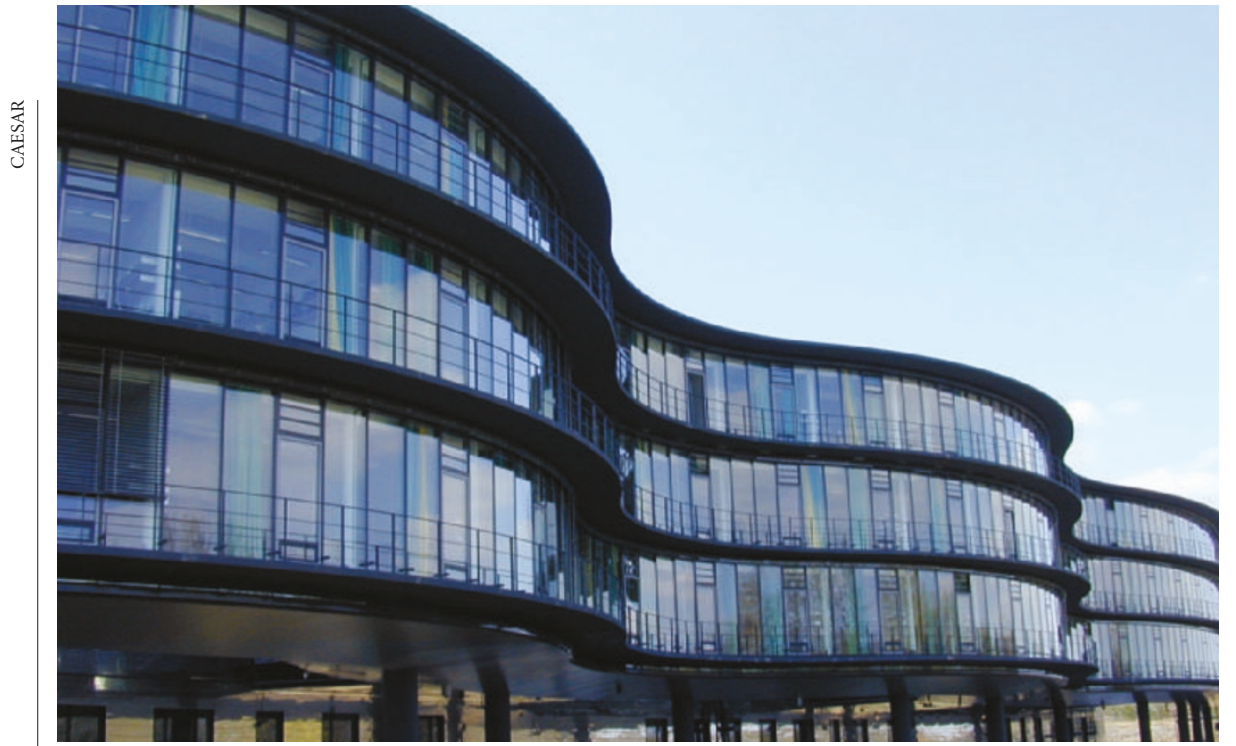

Failing to deliver: the ambitious Center of Advanced European Studies and Research in Bonn.

\title{
Futuristic centre under fire from German science council
}

\section{Quirin Schiermeier, Munich}

An ambitious interdisciplinary research centre, established in Bonn to do innovative work in a futuristic setting, has been found wanting by Germany's science council, the Wissenschaftsrat.

The Center of Advanced European Studies and Research (Caesar) opened in the former West German capital in 1999, with a generous, government-funded endowment of $€ 380$ million (US\$470 million). It was intended to strengthen science in the region and compensate its host city for the government's move to Berlin.

Caesar, whose 110 scientists last year moved into a chic, €60-million laboratory, focuses on the development of technologies and products relevant to industry, based on nanotechnology, biomedical engineering and advanced software design.

But the centre has so far failed to meet expectations, says a review by the council published on 1 June. It finds that too few marketable applications have been developed, and there are not enough publications, patents and spin-offs. Almost half of the centre's 21 groups are underperforming, and the quality-control system is less than satisfactory, the council's external reviewers found.

"Caesar's interdisciplinary concept is certainly worthwhile," says Wedig von Heyden, the council's secretary-general. "But in practice, research gets bogged down. To get back on track, the centre needs to focus on a reduced number of activities - preferably in the life sciences and medical technology."

Successful technologies developed at Caesar so far include a prototype biosensor for environmental analysis, and imaging software that lets oral surgeons design jaw implants in real time during an operation.
But many of the centre's group leaders lack the combination of business and scientific skills needed to find marketable products, says Gerhard Wegner, a scientific director at the Max Planck Institute for Polymer Research in Mainz, who chairs Caesar's scientific advisory committee.

"Caesar's concept and ambitions were over-optimistic from the start,"Wegner says. "To succeed in these difficult markets, you need detailed knowledge about your industrial and scientific competitors, and a solid international standing. But a careful market analysis has never been done, and Caesar is more or less unknown outside Germany." He adds that he is not surprised by the outcome of the review. "The scientific advisory committee has mentioned these problems several times, but we didn't really get heard."

Karl-Heinz Hoffmann, Caesar's scientific director, denies that such advice has been ignored. "Cooperation between the different committees could perhaps have been better," he concedes. But he says he is "disappointed and annoyed" by the amount of criticism now descending on the centre.

Hoffmann says that some of his groups have only been working for three months, and that it is far too early to judge their performance. "We may have been a bit optimistic about the speed of development in, say, nanotechnology. But that is no reason to brush us aside so harshly."

The Wissenschaftsrat has recommended that Caesar's foundation board appoints an independent commission to restructure the centre by the end of next year. In the meantime, it says, no more money should be invested in the centre without the express approval of its grant-givers.

www.caesarde

\section{Nanotech takes small step towards burying 'grey goo'}

Jim Giles

Nanotechnology researchers are sick of hearing about 'grey goo'. Their research is still largely speculative, yet the notion that swarms of tiny self-replicating robots could escape from laboratories and destroy our world comes up time and time again when nanotechnology is discussed with the public.

But researchers can take heart: the author who arguably did most to stir up the fears in the first place has publicly dismissed the scare stories. He says he wishes he had never coined the term 'grey goo', which is used to encapsulate them.

In his 1986 book Engines of Creation, Eric Drexler speculated that selfreplicating robots with molecular-scale dimensions could be used to build everyday goods cheaply and efficiently. He also noted that such 'nanobots' could be dangerous if they escaped: "We cannot afford certain kinds of accidents."

The idea gained a lot of influence, and the term 'grey goo' appears regularly in popular accounts of nanotechnology. It was also the inspiration for Prey, a bestselling 2002 novel by Michael Crichton that is being made into a film.

But in a commentary published on 9 June (see C. Phoenix \& E. Drexler Nanotechnology 15, 869-872; 2004), Drexler acknowledges that nanoscale manufacturing does not require selfreplicating devices. "I wish I had never used the term 'grey goo'," he told Nature.

Drexler says that if he could write Engines of Creation again, he would barely mention self-replicating nanobots. Instead, he would focus on the possibility that nanoscale manufacturing will become a miniature version of conventional processes, in which a single device moves along a conveyor belt and is built up in a series of discrete operations.

The California-based author says he has gone public now because of worries about the way nanotechnology is being perceived. "Fears associated with that old scenario are interfering with current research," says Drexler. "Researchers resent it and I want to clean up the mess."

But Drexler's repentance may not change much. Experts who track public attitudes to nanotechnology say that some environmental groups have played on fears about 'grey goo' to publicize their more genuine concerns about who will benefit from the technology. "If the term wasn't here, the groups would come up with another phrase," says one expert. 